Check for updates

Cite this: Mater. Adv., 2021,

2. 1695

Received 9th October 2020,

Accepted 14th January 2021

DOI: 10.1039/d0ma00782j

rsc.li/materials-advances

\title{
Mesoporous silica-coated gold nanorods loaded with tetrazolyl phthalocyanine as NIR light-activated nano-switches for synergistic photothermal and photodynamic inactivation of antibiotic-resistant Escherichia coli $\dagger$
}

\author{
Qiuhao Ye, ${ }^{a}$ Shuanghuang Xiao, ${ }^{a}$ Ting Lin, ${ }^{b}$ Yufeng Jiang, ${ }^{a}$ Yiru Peng (D)*a and \\ Yide Huang*b
}

\begin{abstract}
A light-controlled nano-switch was prepared by assembling mesoporous silica-coated gold nanorods with bis-(1-(4-hydroxyphenyl)-5-mercapto-tetrazolyl) silicon(Iv) phthalocyanines, which exhibited excellent triple functions with controlled release of phthalocyanines and generation of reactive oxygen species (ROS) as well as temperature enhancement under laser irradiation. The nano-switch achieved an effective antimicrobial activity against a variety of antibiotic-resistant Escherichia coli strains through synergistic photodynamic therapy and photothermal therapy by damaging the genomic DNA and enzyme activity of bacteria.
\end{abstract}

\section{Introduction}

Overuse and misuse of antibiotics by humans for a long time has led to the emergence and prevalence of antibiotic-resistant bacteria, which has reduced the therapeutic efficacy of antibiotics for human and animal pathogens. ${ }^{1-3}$ It is estimated that, by 2050, approximately 10 million people will die directly or indirectly from a multidrug resistant infection. ${ }^{4}$ Despite enormous efforts in research, the development of new antimicrobial drugs cannot catch up with the emergence of antibiotic resistant pathogens. ${ }^{5}$ Pursuit of alternative strategies and drugs to overcome antibiotic resistance is thus highly desirable.

In the past few decades, near-infrared (NIR) laser-induced photothermal therapy (PTT) has been used as a powerful strategy to combat cancers ${ }^{6}$ and bacterial infection ${ }^{7}$ because of its non-invasive manipulation, good controllability, and high tissue penetration. Various photothermal materials have been developed such as gold nanoparticles, ${ }^{8}$ gold nanorods (AuNRs), ${ }^{9}$ carbon nanotubes, ${ }^{10}$ two dimensional $\mathrm{MoS}_{2}{ }^{11}$ and

\footnotetext{
${ }^{a}$ College of Chemistry \& Material, Fujian Provincial Key Laboratory of Advanced Materials Oriented Chemical Engineering, Fujian Province Key Laboratory of Polymer Materials, Fujian Normal University, Fuzhou, China. E-mail: yirupeng@fjnu.edu.cn

${ }^{b}$ Provincial University Key Laboratory of Cellular Stress Response and Metabolic Regulation, College of Life Sciences, Fujian Normal University, Fuzhou, China. E-mail: ydhuang@fjnu.edu.cn

$\dagger$ Electronic supplementary information (ESI) available: Experimental details and characterization data. See DOI: $10.1039 / \mathrm{d} 0 \mathrm{ma} 00782 \mathrm{j}$
}

$\mathrm{MnO}_{2}{ }^{12}$ as well as graphene nanoribbons and their supermolecules. ${ }^{13}$ Mesoporous silica-coated gold nanorods (AuNR-SiO ${ }_{2}$ ) have aroused great interest as photothermal materials because of their tenable surface plasmon resonance and excellent light-to-heat energy conversion efficiency ${ }^{14-17}$ as well as light controllable delivery of biomolecules into cytoplasm. ${ }^{18}$ Besides, the large specific surface area of mesoporous silica guarantees a high drug payload and optimizes the lighttransparent window in the NIR region. ${ }^{19}$ Therefore, AuNR-SiO seems to be a desirable candidate for highly stable and NIR laserinduced antibacterial applications. Turcheniuk et al. reported that AuNR-SiO ${ }_{2}$ loaded with verteporfin could be used as an efficient near infrared nanostructure to eradicate Escherichia coli infection. ${ }^{20}$

Photodynamic therapy (PDT) against microbial cells is also considered to be an alternative high-efficiency strategy to eliminate bacteria both in vitro and in vivo. ${ }^{13,21,22}$ The antibacterial strategy uses a specific wavelength of light to activate photosensitizers (PSs), which react with oxygen to produce reactive oxygen species (ROS) to kill bacteria. Phthalocyanines (Pcs) and metal phthalocyanines (MPcs) have been used as promising photosensitisers for PDT of cancerous and noncancerous diseases. Recently, a series of new Pcs and their nano-formulations have exhibited excellent anticancer ${ }^{23-26}$ and antimicrobial ${ }^{27-31}$ activities. However, the properties of Pcs such as easy aggregation in water, lack of ability to target specific tissue, and a limited optimal wavelength for tissue penetration hinder their applications for PDT. ${ }^{32-34}$ It is desired to synthesize novel Pcs to address the drawbacks of traditional Pcs. 


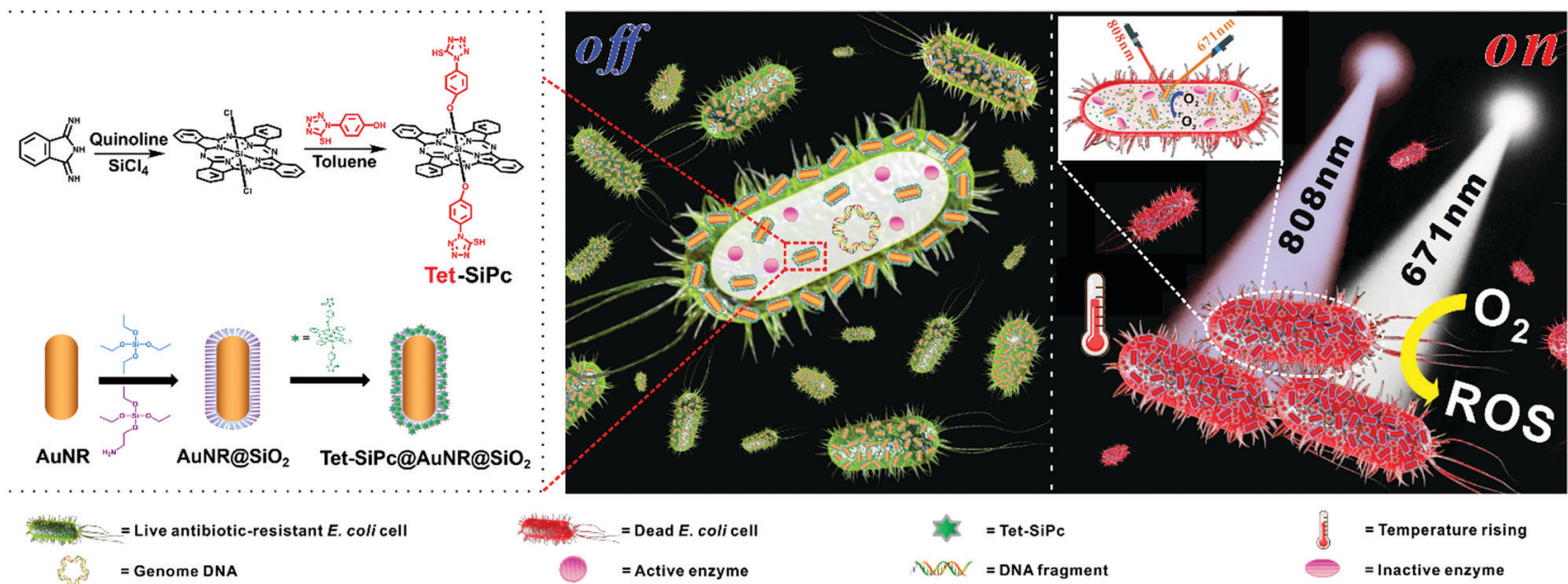

Scheme 1 Schematic representation of the preparation of the Tet-SiPc@AuNR@SiO ${ }_{2}$ nano-switch and the antibacterial mechanism of Tet-SiPcaAuNRaSiO ${ }_{2}$.

In this work, we synthesized a novel silicon Pc with mercaptotetrazolyl functional groups, named bis-(1-(4-hydroxyphenyl)-5mercapto-tetrazolyl)silicon(Iv) phthalocyanine (Tet-SiPc), and used it as a photosensitizer for antibacterial research (Scheme 1). The mercapto-tetrazolyl group, a pharmaceutical synthetic intermediate, is a main pharmacophore of antibacterial and anti-inflammatory drugs. ${ }^{35,36}$ Introducing mercapto-tetrazolyl functional groups to the axial position of Pc rings is expected to reduce its aggregation and improve its photodynamic antibacterial performance. To achieve the synergistic PDT and PTT, a light-controlled nano-switch was assembled through the use of mesoporous silica-coated gold nanorods with bis-(1-(4hydroxyphenyl)-5-mercapto-tetrazolyl) silicon(vv) phthalocyanine. The effect of the nano-switch against a variety of antibioticresistant $E$. coli strains was evaluated.

\section{Materials and methods}

\subsection{Materials and instruments}

The organic solvents used for the preparation of the nanoswitch (Tet-SiPc@AuNR-SiO ${ }_{2}$ ) were of reagent grade. Sodium borohydride $\left(\mathrm{NaBH}_{4}\right)$, silver nitrate $\left(\mathrm{AgNO}_{3}\right)$, sodium hydroxide $(\mathrm{NaOH})$ and hydrochloric acid $(\mathrm{HCl})$ were purchased from Sinopharm Group Chemical Reagent Co., Ltd. Hydrogen tetrachloroaurate(III) trihydrate $\left(\mathrm{HAuCl}_{4} \cdot 3 \mathrm{H}_{2} \mathrm{O}\right)$ was purchased from Shanghai Bailingwei Chemical Technology Co., Ltd. Cetyltrimethylammonium bromide (CTAB) was obtained from Sigma-Aldrich (Mainland, China). 1-(4-Hydroxyphenyl)-5-mercapto-tetrazolium, tetraethyl orthosilicate (TEOS) and 3-aminopropyltriethoxysilane (APTES) were purchased from Energy Chemical. Ascorbic acid (AA) was purchased from the Xinning Chemical Plant in Shantou (Guangdong, China).

The infrared spectra ( $\mathrm{KBr}$ pellets) were recorded on a PE-983G spectrometer. ${ }^{1} \mathrm{H}$ NMR spectra were recorded on a Bruker $400 \mathrm{MHz}$ FT-NMR spectrometer using tetramethylsilane (TMS) as an internal standard. Mass spectra (MS) were measured on a Bruker MALDI-TOF mass spectrometer. UV/Vis spectra were recorded on a Cary $50 \mathrm{UV} / \mathrm{Vis}$ spectrophotometer. Fluorescence emission spectra were measured on an FL900/FS920 fluorescence spectrophotometer. Raman spectra were recorded on the XploRA Plus system. The particle size distribution was analyzed using a Mastersizer 3000E laser particle size analyser. Energy dispersive X-ray spectroscopy (EDX) was performed on an FESEM-7500F scanning electron microscope (SEM). Element analysis via Inductively Coupled Plasma Optical Emission Spectrometry (ICP-OES) was performed on a PerkinElmer Optima 8000. A Mithras LB 940 multimode microplate reader was used to detect enzyme activity. Transmission electron microscopy (TEM) images were obtained using a JEM 1400 transmission electron microscope at an acceleration voltage of $100 \mathrm{kV}$.

\subsection{Synthesis of bis-(1-(4-hydroxyphenyl)-5-mercapto- tetrazolyl)silicon(Iv) phthalocyanine (Tet-SiPc)}

A mixture of dichloro-phthalocyanine silicon $\left(\mathrm{SiPcCl}_{2}\right)(0.061 \mathrm{~g}$, $0.1 \mathrm{mmol}){ }^{37}$ 1-(4-hydroxyphenyl)-5-mercapto-tetrazole (Tet) $(0.05826 \mathrm{~g}, 0.3 \mathrm{mmol})$ and potassium carbonate $(0.028 \mathrm{~g}$, $0.2 \mathrm{mmol})$ in toluene $(30 \mathrm{~mL})$ was heated at $110{ }^{\circ} \mathrm{C}$ for $48 \mathrm{~h}$. The mixture was cooled to room temperature and the solvent was removed by filtration. After evaporation under reduced pressure, the crude product was purified twice via alumina column chromatography using acetone and hexane $(\mathrm{v}: \mathrm{v}=1: 5)$ and methanol and methylene chloride $(\mathrm{v}: \mathrm{v}=1: 10)$ as eluents, respectively. The obtained product was further purified twice via chromatography on a silica gel column using acetone and methylene chloride ( $\mathrm{v}: \mathrm{v}=1: 10)$ as eluents. Tet-SiPc was obtained as a dark blue-green solid in a yield of $18 \%$. IR $\nu / \mathrm{cm}^{-1}: 736(\mathrm{Ar}-\mathrm{H})$, 1080 (Si-O), 1240 (C-O), 1506 (C-N); Raman $\nu / \mathrm{cm}^{-1}: 681\left(\sigma_{\mathrm{C}-\mathrm{H}}\right)$, $1342(\mathrm{C}-\mathrm{N}), 1524(\mathrm{C}=\mathrm{N}), 1612\left(\sigma_{\mathrm{C}=\mathrm{C}}\right) ;{ }^{1} \mathrm{H}$ NMR $(400 \mathrm{MHz}$, DMSO-d $\left.\mathrm{d}_{6}\right) \delta / \mathrm{ppm}: 8.95\left(2 \mathrm{H}, \mathrm{s}, \mathrm{SH}, \mathrm{D}_{2} \mathrm{O}\right.$ exchange, $\left.\mathrm{H}^{1}\right), 5.17(4 \mathrm{H}$, $\left.\mathrm{d}, J=8 \mathrm{~Hz}, \mathrm{H}^{2}\right), 2.28\left(4 \mathrm{H}, \mathrm{d}, J=8 \mathrm{~Hz}, \mathrm{H}^{3}\right), 8.53-8.56\left(8 \mathrm{H}, \mathrm{m}, \mathrm{H}^{4}\right)$, 9.68-9.70 $\left(8 \mathrm{H}, \mathrm{m}, \mathrm{H}^{5}\right)$; ESI-MS calcd for $m / z=926.16$, found: $m / z=925.63[\mathrm{M}]^{+}$. 
2.3. Preparation of mesoporous silica-coated gold nanorods loaded with bis-(1-(4-hydroxyphenyl)-5-mercaptotetrazolyl)silicon(Iv) phthalocyanine (Tet-SiPc@AuNR@SiO

AuNRs were synthesized according to the seed-mediated growth method described by Babak et al. ${ }^{38}$ Firstly, CTAB solution $(10 \mathrm{~mL}, 0.10 \mathrm{M})$ was mixed with $\mathrm{HAuCl}_{4}$ solution (50 $\mu \mathrm{L}, 50 \mathrm{mM}$ ). Subsequently, ice-cold $\mathrm{NaBH}_{4}$ solution $(600 \mu \mathrm{L}, 0.01 \mathrm{M})$ was added to the mixture, followed by stirring at $25{ }^{\circ} \mathrm{C}$ for $3 \mathrm{~min}$, resulting in the formation of a brown seed solution. In order to grow the gold seeds, the seed solution was allowed to stand for $2 \mathrm{~h}$. The nanorod growth solution was prepared by mixing $\mathrm{HAuCl}_{4}$ solution $(300 \mu \mathrm{L}, 50 \mathrm{mM})$ and CTAB solution $(30 \mathrm{~mL}, 0.10 \mathrm{M})$ with gentle stirring, then $\mathrm{AgNO}_{3}$ solution $(300 \mu \mathrm{L}, 0.10 \mathrm{M}), \mathrm{HCl}$ solution $(300 \mu \mathrm{L}, 1.0 \mathrm{M})$ and ascorbic acid $(240 \mu \mathrm{L}, 0.10 \mathrm{M})$ were added in sequence to prepare the growth solution.

To grow the gold nanorods, the seed solution $(75 \mu \mathrm{L})$ was added to the growth solution under slow stirring, and the mixture was continuously stirred at $25{ }^{\circ} \mathrm{C}$ overnight to obtain a purple-red gold nanorod mixture, then the mixture was centrifuged at $8000 \mathrm{rpm}$ for $10 \mathrm{~min}$ and washed with ultrapure water three times. Finally, the product, AuNRs, was dispersed in $30 \mathrm{~mL}$ of ultra-pure water for further use.

For preparing the mesoporous silica-coated gold nanorods, ${ }^{39} \mathrm{NaOH}$ solution $(0.10 \mathrm{M})$ was added into the above prepared AuNR solution with stirring to adjust the $\mathrm{pH}$ of the mixed solution to 10 . Next, tetraethyl orthosilicate (TEOS) (20\%, $30 \mu \mathrm{L}$ ) in methanol and $10 \mu \mathrm{L}$ of $2 \% 3$-aminopropyltriethoxysilane (APTES) in methanol were injected into the AuNR solution three times at $30 \mathrm{~min}$ intervals. The mixed solution was stirred for $24 \mathrm{~h}$ at $25{ }^{\circ} \mathrm{C}$ to obtain AuNR@SiO ${ }_{2}$. Finally, the synthesized AuNR@SiO ${ }_{2}$ was collected via centrifugation at $8000 \mathrm{rpm}$ for $5 \mathrm{~min}$ and washed three times with ultra-pure water to remove CTAB. The product was dispersed in $30 \mathrm{~mL}$ of ultra-pure water for further use. The concentrations of gold in AuNRs and AuNR@SiO ${ }_{2}$ were determined by using element analysis via Inductively Coupled Plasma Optical Emission Spectrometry (ICP-OES).

To prepare Tet-SiPc@AuNR@SiO ${ }_{2}$, Tet-SiPc DMSO solution $(50 \mu \mathrm{L}, 1 \mathrm{mM})$ was added to the AuNR@SiO ${ }_{2}$ solution $(10 \mathrm{~mL})$, the gold concentration of which was $200 \mu \mathrm{g} \mathrm{mL} \mathrm{m}^{-1}$ as determined via ICP-OES. The mixture was stirred at room temperature for $48 \mathrm{~h}$. The obtained product solution was centrifuged at $8000 \mathrm{rpm}$ for $5 \mathrm{~min}$, followed by consecutive washing three times with ultra-pure water, and Tet-SiPc@AuNR@SiO ${ }_{2}$ was then dispersed in $10 \mathrm{~mL}$ of ultrapure water for further use.

\subsection{Fluorescence quantum yields of Tet-SiPc}

Fluorescence quantum yields $\left(\Phi_{\mathrm{F}}\right)$ of Tet-SiPc in DMSO were determined by using the comparative method of Eq. $1:^{40}$

$$
\Phi_{\mathrm{F}}=\Phi_{\mathrm{F}(\mathrm{std})} \cdot F \cdot A_{\mathrm{Std}} \cdot n^{2} /\left(F_{\mathrm{Std}} \cdot A \cdot n_{\mathrm{std}}^{2}\right)
$$

where the integral areas of the emission curves of Tet-SiPc and unsubstituted ZnPc ( $n$-ZnPc) are denoted by $F$ and $F_{\text {Std }}$, respectively. The absorbance of Tet-SiPc and standard $n$-ZnPc at the excitation wavelength are represented by $A$ and $A_{\mathrm{Std}}$, respectively. The refractive indices of Tet-SiPc and standard $n$-ZnPc solvents are represented by $n^{2}$ and $n_{\text {std }}^{2}$, respectively. $n$-ZnPc in DMSO $\left(\Phi_{\mathrm{F}(\mathrm{std})}=0.20\right)$ was employed as the standard. ${ }^{41}$

\subsection{Singlet oxygen quantum yields of Tet-SiPc}

Singlet oxygen quantum yields $\left(\Phi_{\Delta}\right)$ of Tet-SiPc were measured by the chemical trapping method based on the singlet oxygen quencher 1,3-diphenylisobenzofuran (DPBF). ${ }^{42}$ Tet-SiPc $(3 \mathrm{~mL}$, $\left.3 \times 10^{-6} \mathrm{M}\right)$ and DPBF $\left(6 \times 10^{-5} \mathrm{M}\right)$ were mixed using DMSO as the solvent, and the mixture was continuously irradiated with a laser $\left(671 \mathrm{~nm}, 100 \mathrm{~mW} \mathrm{~cm} \mathrm{~cm}^{-2}\right)$. The decrease of DPBF absorbance at $417 \mathrm{~nm}$ was detected from the UV-Vis spectra. Using $n$-ZnPc as the reference ( $\Phi_{\Delta}=0.67$ for $n$-ZnPc in DMSO), ${ }^{43}$ the $\Phi_{\Delta}$ value of Tet-SiPc was calculated using Eq. 2:

$$
\Phi_{\Delta}=\Phi_{\Delta} \mathrm{Std} \cdot \frac{R}{R^{\mathrm{Std}}} \cdot \frac{I_{\mathrm{Abs}}^{\mathrm{Std}}}{I_{\mathrm{Abs}}}
$$

\subsection{Singlet oxygen quantum yields of AuNRs, AuNR@SiO and Tet-SiPc@AuNR@SiO}

Singlet oxygen was monitored via chemical oxidation of 9,10anthracenediyl-bis(methylene)dimalonic acid (ABDA) $\left(3 \times 10^{-4} \mathrm{M}\right)$ in the presence of AuNRs, AuNR@SiO ${ }_{2}$ or Tet-SiPc@AuNR@ $\mathrm{SiO}_{2}$, the gold concentration of which was found to be $100 \mu \mathrm{g} \mathrm{mL}{ }^{-1}$ via ICP-OES. $^{20}$ The decrease in ABDA absorbance at $378 \mathrm{~nm}$ was monitored upon laser irradiation $(671 \mathrm{~nm}$,

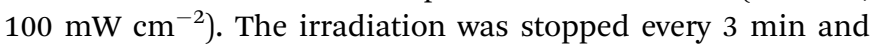
UV-Vis absorption spectra were recorded.

\subsection{The loading rate of Tet-SiPc on AuNR@SiO}

The loading rate of Tet-SiPc on AuNR@SiO ${ }_{2}$ was measured according to the method described by Chen et al. ${ }^{10}$ The loading rate of Tet-SiPc on AuNR@SiO ${ }_{2}$ was calculated according to eqn (3):

$$
f=\frac{M_{\mathrm{Tet}-\mathrm{SiPc}}-M_{\mathrm{Tet}-\mathrm{SiPc}^{\prime}}}{M_{\mathrm{Tet}-\mathrm{SiPc} @ \mathrm{AuNR} @ \mathrm{SiO}_{2}}} \times 100 \%
$$

where $f$ is the loading rate of Tet-SiPc on AuNR@SiO ${ }_{2}, M_{\mathrm{Tet}-\mathrm{SiPc}}$ is the initial amount of Tet-SiPc, $M_{\mathrm{Tet}^{-S_{P} c^{\prime}}}$ is the amount of Tet-SiPc in solution and $M_{\text {Tet-SiPc@AuNR@SiO2 }}$ is the amount of Tet-SiPc@AuNR@SiO ${ }_{2}$ added.

\subsection{The photo-induced release of Tet-SiPc from Tet- SiPc@AuNR@SiO}

The photo-induced release of Tet-SiPc from Tet-SiPc@AuNR@ $\mathrm{SiO}_{2}$ was studied via fluorescence spectroscopy. ${ }^{10} \mathrm{In}$ brief, $3 \mathrm{~mL}$ of Tet-SiPc@AuNR@SiO ${ }_{2}$ solution with a $100 \mu \mathrm{g} \mathrm{mL}^{-1}$ gold concentration was added to seven centrifuge tubes, respectively. Each centrifuge tube was irradiated with an infrared laser ( $808 \mathrm{~nm}, 0.5 \mathrm{~W} \mathrm{~cm}^{-2}$ ) and a thermocouple thermometer was used to record the temperature of the Tet-SiPc@ AuNR@SiO ${ }_{2}$ solution every one minute. AuNR@SiO ${ }_{2}$, AuNRs and ultra-pure water were used as controls. At the same time, the Tet-SiPc released from Tet-SiPc@AuNR@SiO ${ }_{2}$ was 
monitored via fluorescence spectroscopy. Tet-SiPc@AuNR@ $\mathrm{SiO}_{2}$ solution was irradiated to release Tet-SiPc which was insoluble in solution at $808 \mathrm{~nm}\left(0.5 \mathrm{~W} \mathrm{~cm}^{-2}\right)$. After the solutions were irradiated for $0,5,10,15,20$ and $25 \mathrm{~min}$. Tet-SiPc is insoluble in the solution, the precipitation of Tet-SiPc was centrifuged and re-dissolved in DMSO. The fluorescence of the Tet-SiPc solution obtained above was measured and the concentration of Tet-SiPc was calculated.

\subsection{Construction of antibiotic-resistant $E$. coli DH5 $\alpha$ strains and expression of $\beta$-galactosidase in $E$. coli DH5 $\alpha$ cells}

E. coli $\mathrm{DH} 5 \alpha$ cells are not resistant to Ampicillin, Kanamycin and Zeocin. The Ampicillin-, Kanamycin- or Zeocin-resistant E. coli $\mathrm{DH} 5 \alpha$ strain could be created by transforming a plasmid containing a corresponding antibiotic-resistant gene. In this study, pUC18, pET28a and pPICZa plasmids were used to transform E. coli DH5 $\alpha$. pUC18, pET28a and pPICZa contain an Ampicillin-, a Kanamycin- and a Zeocin-resistant gene, respectively. After successful transformation, E. coli DH5 $\alpha$ will gain the ability to resist Ampicillin, Kanamycin or Zeocin. The LB plates containing Ampicillin $\left(100 \mu \mathrm{g} \mathrm{mL}{ }^{-1}\right)$, Kanamycin $\left(50 \mu \mathrm{g} \mathrm{mL}{ }^{-1}\right)$ or Zeocin $\left(25 \mu \mathrm{g} \mathrm{mL}{ }^{-1}\right)$ were used to confirm the ability of the transformed $E$. coli $\mathrm{DH} 5 \alpha$ to resist the corresponding antibiotics.

$\beta$-Galactosidase is an important enzyme to metabolize the lactose in $E$. coli, but the LacZ gene encoding $\beta$-galactosidase is mutated in $E$. coli $\mathrm{DH} 5 \alpha$, which causes the loss of the $\beta$-galactosidase activity. To regain the activity of $\beta$-galactosidase in $E$. coli $\mathrm{DH} 5 \alpha$, a recombinant plasmid expressing the functional $\beta$-galactosidase was constructed by using the pAO815 plasmid as the backbone. The pAO815 was linearized via digestion with the EcoR I restriction enzyme. The LacZ gene with full length was amplified using the plasmid pAd/CMV/V5-GW/lacZ as a template and a pair of specific primers (forward primer: 5'CCGGAATTCACCATGATAGATCCCGTCG $3^{\prime}$, reverse primer: $5^{\prime}$ CCGGAATTCTATTTTTGACACCAGACCAACTG $3^{\prime}$ ) flanked by an EcoR I site at both $5^{\prime}$ and $3^{\prime}$ ends via PCR. The PCR product was purified by using the Promega Wizard SV Gel and PCR Clean-up System (Promega (Beijing) Biotech Co., Ltd. Beijing, China). The purified PCR product was digested using EcoR I and then ligated with the linearized pAO815 plasmid using T4 DNA ligase. The recombinant plasmid was confirmed by DNA sequencing and transformed into E. coli $\mathrm{DH} 5 \alpha$. The expression of $\beta$-galactosidase was verified on the LB plate containing 5-bromo-4-chloro-3-indolyl $\beta$-D-galactoside (X-Gal), a chromogenic substrate for $\beta$-galactosidase.

\subsection{Antibacterial activity of Tet-SiPc@AuNR@SiO ${ }_{2}$ against} E. coli DH5 $\alpha$ and antibiotic-resistant $E$. coli DH5 $\alpha$ strains

E. coli $\mathrm{DH} 5 \alpha$ or antibiotic-resistant strains were cultured in the LB (Luria-Bertani) medium at $37{ }^{\circ} \mathrm{C}$ overnight until $\mathrm{OD}_{600 \mathrm{~nm}}$ reached about 0.5 . The culture was then diluted $1: 10$ in the $\mathrm{LB}$ medium. $40 \mu \mathrm{L}$ of Tet-SiPc@AuNR@SiO ${ }_{2}\left(C_{\mathrm{Au}}=100 \mu \mathrm{g} \mathrm{mL}{ }^{-1}\right)$ in sterile distilled water was added into $20 \mu \mathrm{L}$ of bacterial dilution. The suspension was illuminated using $808 \mathrm{~nm}$ laser light at $0.5 \mathrm{~W} \mathrm{~cm}^{-2}$ for $5 \mathrm{~min}$ and then irradiated using a $671 \mathrm{~nm}$ laser for $10 \mathrm{~min}$ with a power density of $100 \mathrm{~mW} \mathrm{~cm}^{-2}$. After the combined irradiation at $808 \mathrm{~nm}$ and $671 \mathrm{~nm}$, a series of 10-fold dilutions of the bacteria were performed with the LB medium, and $5 \mu \mathrm{L}$ of each dilution was dropped on LB agar plates and incubated at $37^{\circ} \mathrm{C}$ for $12-16 \mathrm{~h}$ until the colonies appeared. For the colony forming unit (CFU) assay or relative survival rate analysis, an aliquot $(200 \mu \mathrm{L})$ of the above diluted bacterial suspension was plated on a $10 \mathrm{~cm}$ LB agar plate. The plates were incubated at $37^{\circ} \mathrm{C}$ for $12-16 \mathrm{~h}$ until the colonies appeared, and then the total number of colonies on each plate was counted. The number of $\mathrm{CFU} \mathrm{mL}^{-1}$ was calculated as the number of colonies counted on a plate/0.2 $\mathrm{mL}$ and the dilution factor. The cell survival rate was calculated via normalization with respect to the CFU value of the control group performed without the treatment of Tet-SiPc@AuNR@SiO ${ }_{2}$. Each experiment was repeated three times.

\subsection{Effect of Tet-SiPc@AuNR@SiO ${ }_{2}$ on the genomic DNA damage of $E$. coli $\mathrm{DH} 5 \alpha$}

The genomic DNA of $E$. coli DH5 $\alpha$ with or without the treatment of Tet-SiPc@AuNR@SiO ${ }_{2}$ under combined laser irradiation at $808 \mathrm{~nm}$ and $671 \mathrm{~nm}$ as mentioned above was extracted by using the genomic DNA extraction kit (Tiangen (Beijing) Biotech Co., Ltd Beijing, China) and quantified using a NanoDrop 2000 spectrophotometer (Thermo Fisher Scientific, Wilmington, DE, USA). $500 \mu \mathrm{g}$ of genomic DNA was loaded into wells of a $1 \%$ agarose gel, and then electrophoresis was performed at $100 \mathrm{~V}$ for $30 \mathrm{~min}$. The gel was stained with ethidium bromide and photographed.

\subsection{Effect of Tet-SiPc@AuNR@SiO ${ }_{2}$ on the enzyme activity of $\beta$-galactosidase}

The engineered $E$. coli DH5 $\alpha$ cells expressing the functional $\beta$-galactosidase were treated with or without Tet-SiPc@AuNR@ $\mathrm{SiO}_{2}$ under combined laser irradiation at $808 \mathrm{~nm}$ and $671 \mathrm{~nm}$ as mentioned above. The bacterial cells were collected via centrifugation at $10000 \mathrm{rpm}$ for $5 \mathrm{~min}$. After discarding the supernatant, the pellets were resuspended with Z-buffer $\left(\mathrm{Na}_{2} \mathrm{HPO}_{4} 60 \mathrm{mM}, \mathrm{NaH}_{2} \mathrm{PO}_{4} 40 \mathrm{mM}\right.$, KCl $10 \mathrm{mM}, \mathrm{MgSO}_{4}$ $1 \mathrm{mM}, \mathrm{pH}=7.0$ ) with $\beta$-mercaptoethanol (adding $0.27 \mathrm{~mL}$ $\beta$-mercaptoethanol to $100 \mathrm{~mL}$ of Z-buffer), and then 3 drops of chloroform and 2 drops of $0.1 \%$ sodium dodecyl sulfonate (SDS) were added, followed by vortexing at $3000 \mathrm{rpm}$ for $10 \mathrm{~s}$, and this procedure was repeated three times. After incubating the bacterial solution at $28{ }^{\circ} \mathrm{C}$ for $5 \mathrm{~min}, 200 \mu \mathrm{L}$ of 2 -nitrophenyl- $\beta$-D-galactopyranoside (ONPG) $\left(4 \mathrm{mg} \mathrm{mL} \mathrm{mL}^{-1}\right.$ in Z-buffer) was added and incubated at $30{ }^{\circ} \mathrm{C}$ until a yellow colour developed. The elapsed time was recorded in minutes. After the yellow colour developed, $500 \mu \mathrm{L}$ of $1 \% \mathrm{Na}_{2} \mathrm{CO}_{3}$ solution was added. The reaction tubes were centrifuged for $10 \mathrm{~min}$ at $14000 \mathrm{rpm}$ to pellet cell debris, and the supernatants were carefully transferred into a 96-well plate. Finally, the developed yellow colour was measured at $420 \mathrm{~nm}$ on a spectrophotometer. The enzyme activity of $\beta$-galactosidase was calculated according to eqn (4) and the enzyme activity of control (no treatment with 
Tet-SiPc@AuNR@SiO ${ }_{2}$ ) was normalized to 100\%:

$$
\text { Enzyme activity }=\frac{\mathrm{OD}_{420 \mathrm{~nm}}}{\mathrm{OD}_{600 \mathrm{~nm}} \times V \times t}
$$

where $V$ is the volume of the bacterial solution $(\mathrm{mL})$ and $t$ is the reaction time ( $\mathrm{min})$.

\section{Results and discussion}

\subsection{Synthesis and characterization of Tet-SiPc}

Tet-SiPc was obtained via a nucleophilic substitution reaction between 1-(4-hydroxyphenyl)-5-mercapto-tetrazole and dichloro-silicon phthalocyanine $\left(\mathrm{SiPcCl}_{2}\right)$ using anhydrous $\mathrm{K}_{2} \mathrm{CO}_{3}$ as the catalyst in a yield of $18 \%$ (Scheme 1 ). The chemical structure of Tet-SiPc was characterized by various methods including ${ }^{1} \mathrm{H}$ NMR, ESI-MS, FT-IR and Raman spectroscopy (Fig. S1-S4, ESI $\dagger$ ). The UV/Vis spectra of Tet-SiPc in dimethyl sulfoxide (DMSO) showed typical spectra of Pc with a B band at $355 \mathrm{~nm}$ and a $Q$ band at $683 \mathrm{~nm}$ (Fig. 1a). With the increase of the concentration of Tet-SiPc, the intensity of the $\mathrm{Q}$ band was enhanced, while the shape and position of the $\mathrm{Q}$ band did not change, indicating that the introduction of mercaptotetrazole functional groups could reduce the aggregation of Pcs. Upon excitation at $615 \mathrm{~nm}$, Tet-SiPc showed emission at $677 \mathrm{~nm}$ (Fig. 1b). The fluorescence lifetime of Tet-SiPc was found to be $5.23 \mathrm{~ns}$, and the fluorescence quantum yield $\left(\Phi_{\mathrm{F}}\right)$ was calculated to be 0.0522 (Table S1 and Fig. S5, ESI $\dagger$ ). The quantum yield of singlet oxygen $\left({ }^{1} \mathrm{O}_{2}\right)\left(\Phi_{4}\right)$ was found to be 0.355 (Table S1 and Fig. S6, ESI $\dagger$ ).

\subsection{Preparation and characterization of AuNRs, AuNR@SiO and Tet-SiPc@AuNR@SiO}

In order to enhance the antibacterial efficiency of Tet-SiPc and reduce its phototoxicity, AuNR-SiO $\mathrm{S}_{2}$ was used as a nanocarrier to load Tet-SiPc to form a novel light control nano-switch (Tet-SiPc@AuNR-SiO ${ }_{2}$ ). The Tet-SiPc@AuNR-SiO ${ }_{2}$ was prepared through the adsorption of Tet-SiPc on AuNR-SiO ${ }_{2}$. Briefly,
AuNRs were synthesized using the seed-mediated growth method. ${ }^{38}$ AuNR@SiO 2 , a mesoporous silica layer wrapped on the surface of AuNRs, was prepared by an improved method. ${ }^{39}$ Tet-SiPc (1 mM) was added to the aqueous solution of AuNR@ $\mathrm{SiO}_{2}\left(200 \mu \mathrm{g} \mathrm{mL}^{-1}\right)$ and stirred for $48 \mathrm{~h}$. After being centrifuged and dialyzed, Tet-SiPc@AuNR@SiO ${ }_{2}$ was obtained (Scheme 1). The TEM images showed that AuNRs, AuNR@SiO ${ }_{2}$ and TetSiPc@AuNR@SiO ${ }_{2}$ exhibited uniform size and good dispersion in solution (Fig. 2a-c). The average length and width of AuNRs were about $59 \mathrm{~nm}$ and $16 \mathrm{~nm}$, respectively, and the aspect ratio (AR) was calculated to be about 3.70. The thickness of the initial silica coating was measured to be about $22 \mathrm{~nm}$ for AuNR@SiO${ }_{2}$. After the Tet-SiPc was successfully loaded into the mesoporous silica of AuNR@SiO ${ }_{2}$, the colour of the silica coating layer became darker due to the contribution of the high electron density of Tet-SiPc. The dynamic light scattering (DLS) size of AuNRs was found to be $31 \mathrm{~nm}$. After the mesoporous silica was coated on AuNRs, the DLS size of AuNR@SiO ${ }_{2}$ increased from $31 \mathrm{~nm}$ to $67 \mathrm{~nm}$. With further loading of Tet-SiPc on AuNR@ $\mathrm{SiO}_{2}$, the DLS size of Tet-SiPc@AuNR@SiO ${ }_{2}$ was increased to $106 \mathrm{~nm}$ (Fig. 2d-f). The average particle sizes measured via DLS were larger than those measured via TEM, which could be related to the swelling of nanoparticles in solution. ${ }^{44}$ Energy dispersive X-ray spectroscopy (EDX) was used to demonstrate the successful loading of Tet-SiPc on AuNR@SiO ${ }_{2}$. The content of $\mathrm{N}$ element in AuNR@SiO $\mathrm{S}_{2}$ was significantly higher than that in AuNRs, and the element of $\mathrm{Si}$ appeared at AuNR@SiO indicating the successful coating of $\mathrm{SiO}_{2}$ on AuNRs (Fig. S7 and S8, Table S2 and S3, ESI $\dagger$ ). The presence of S element in Tet-SiPc@AuNR@SiO ${ }_{2}$ proved the successful loading of Tet-SiPc on Tet-SiPc@AuNR@SiO ${ }_{2}$ (Fig. S9, Table S4, ESI $\dagger$ ). The successful preparation of Tet-SiPc@AuNR@SiO ${ }_{2}$ was also confirmed by the UV/Vis absorption spectra (Fig. 2g). The AuNRs exhibited two surface plasmon resonance absorption peaks. The lateral surface plasmon resonance absorption peak was located at $514 \mathrm{~nm}$ and the longitudinal surface plasmon resonance absorption peak was found to be at $801 \mathrm{~nm}$. After the
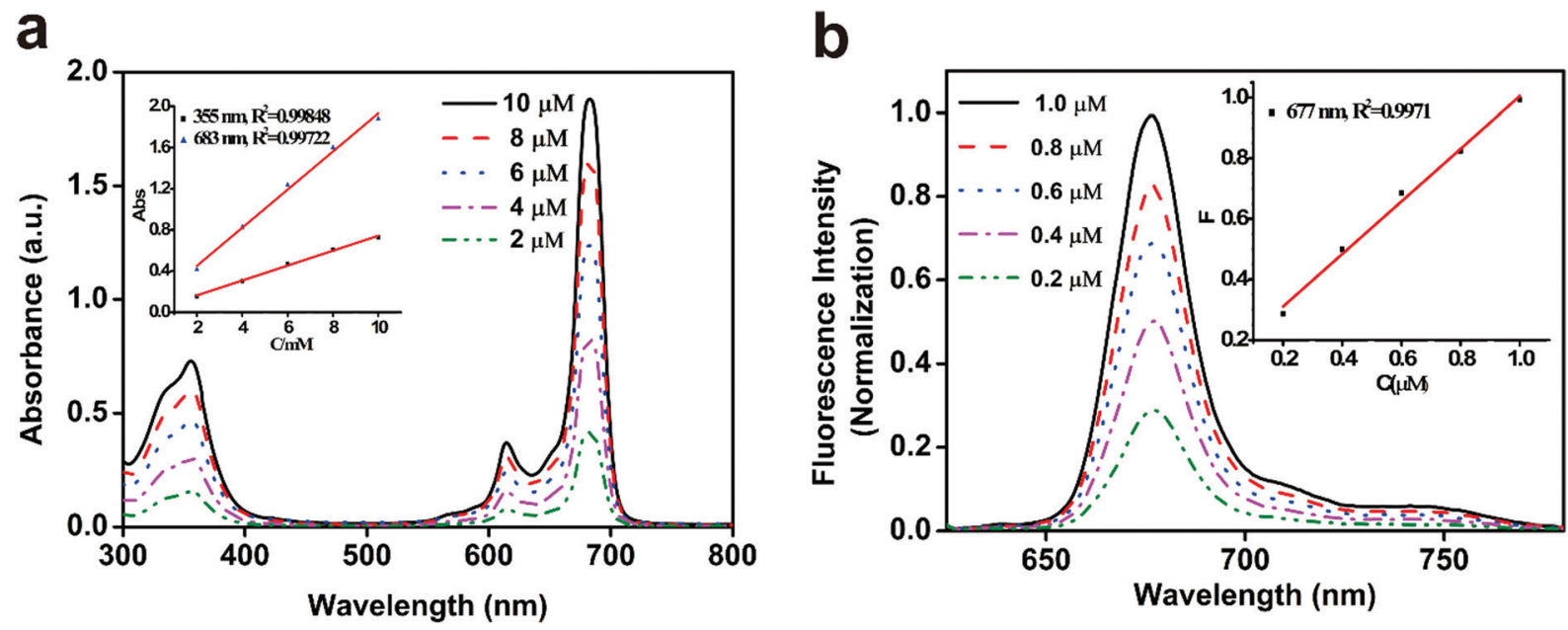

Fig. 1 (a) UV-visible spectra of Tet-SiPc in DMSO; (b) fluorescence spectra of Tet-SiPc in DMSO ( $\left.\lambda_{\mathrm{ex}}=615 \mathrm{~nm}\right)$. 

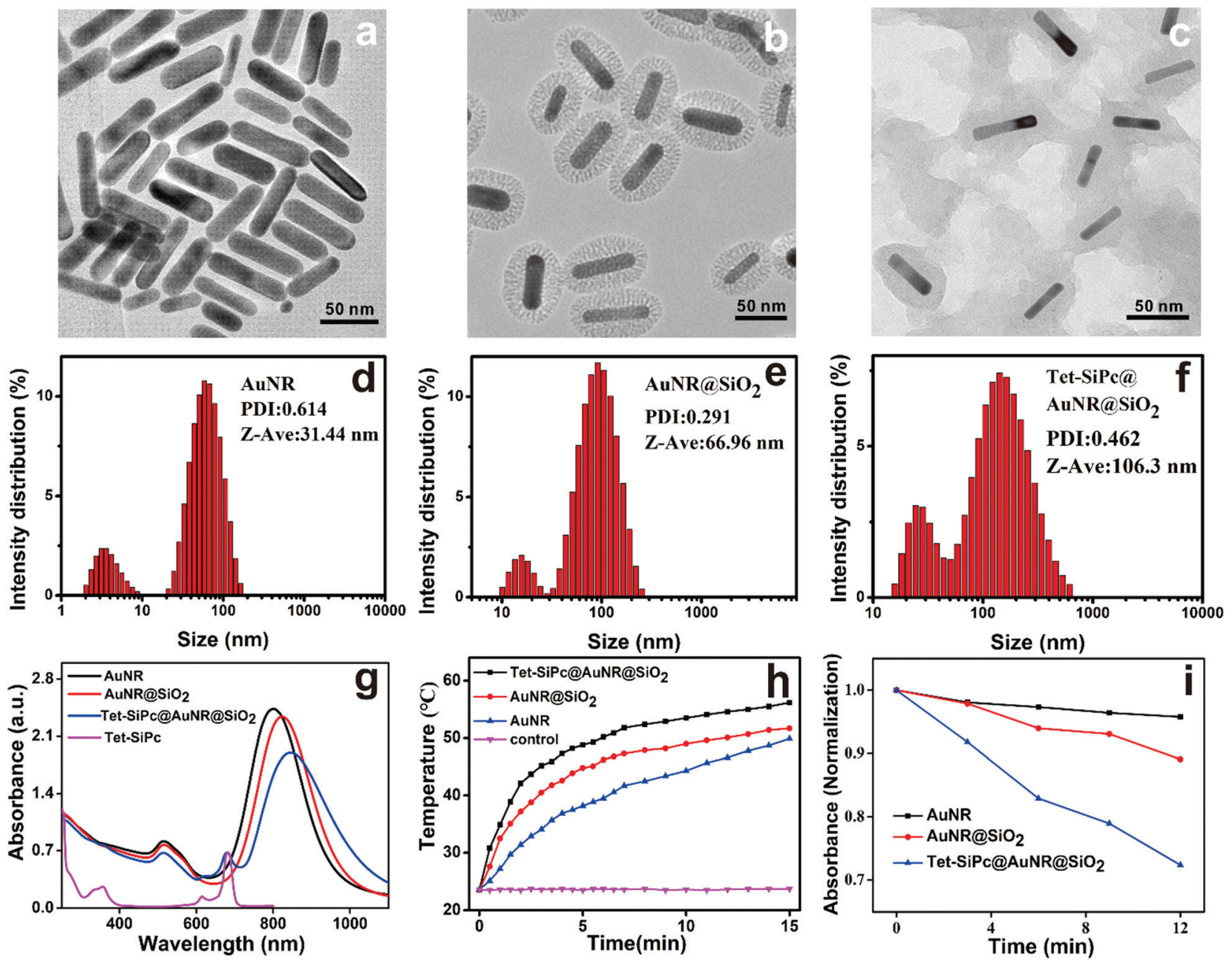

Fig. 2 TEM images of (a) AuNRs, (b) AuNR@SiO 2 and (c) Tet-SiPc@AuNR@SiO Tet-SiPc@AuNR@SiO ${ }_{2}$ in water; $(\mathrm{g})$ UV-Vis absorption spectra of AuNRs, AuNR@SiO 2 and Tet-SiPcaAuNR@SiO $2\left(C_{\mathrm{Au}}=6.5 \mu \mathrm{g} \mathrm{mL}{ }^{-1}\right)$; (h) $\mathrm{curves}$ of temperature change of AuNRs, AuNRaSiO ${ }_{2}$ and Tet-SiPc@AuNR@SiO 2 solutions under laser irradiation (808 nm laser with a power density of $0.5 \mathrm{~W} \mathrm{~cm}^{-2}$. PBS solution as a control; the gold concentration in AuNRs, AuNR@SiO 2 and Tet-SiPc@AuNR@SiO ${ }_{2}$ was $100 \mu \mathrm{g} \mathrm{mL}{ }^{-1}$ ); (i) curves of the absorption change of ABDA mixed with AuNRs, AuNR@SiO ${ }_{2}$ or Tet-SiPc@AuNR@SiO ${ }_{2}$ for different irradiation times $(671 \mathrm{~nm}$ laser with a power density of $100 \mathrm{~mW} \mathrm{~cm}^{-2}$ ). The gold concentration of AuNRs, AuNR(ASiO 2 and Tet-SiPcaAuNR@SiO 2 was $100 \mu \mathrm{g} \mathrm{mL}^{-1}$.

AuNRs were coated with mesoporous silica, the shape and position of the lateral characteristic absorption peak at $514 \mathrm{~nm}$ were unchanged, while the longitudinal surface plasmon resonance was red-shifted from $801 \mathrm{~nm}$ to $824 \mathrm{~nm}$. In the absorption spectrum of Tet-SiPc@AuNR@SiO ${ }_{2}$, a characteristic absorption peak of Tet-SiPc was observed at $683 \mathrm{~nm}$ and the longitudinal surface plasmon resonance absorption peak of AuNRs continued to redshift to $845 \mathrm{~nm}$, indicating that Tet-SiPc was successfully loaded in AuNR@SiO ${ }_{2}$. The loading ratio of Tet-SiPc in Tet-SiPc@AuNR@SiO ${ }_{2}$ was calculated to be $48 \%$ using UV-Vis absorption spectra. The photothermal effect of AuNRs, AuNR@SiO ${ }_{2}$ and Tet-SiPc@AuNR@SiO ${ }_{2}$ irradiated using an $808 \mathrm{~nm}$ laser with a power density of $0.5 \mathrm{~W} \mathrm{~cm}^{-2}$ for 15 min was shown in Fig. 2h. AuNRs, AuNR@SiO ${ }_{2}$ and Tet-SiPc@AuNR@SiO ${ }_{2}$ exhibited excellent photothermal properties. The temperature of AuNRs, AuNR@SiO $\mathrm{Si}_{2}$ and Tet-SiPc@ AuNR@SiO ${ }_{2}$ increased to $49.9,51.7$ and $56.2{ }^{\circ} \mathrm{C}$ after $15 \mathrm{~min}$ illumination, respectively. Tet-SiPc@AuNR@SiO $\mathrm{S}_{2}$ possessed the highest photothermal conversion efficiency, which is probably due to the theranostic photothermal effect of Tet-SiPc loaded on the mesoporous silica and AuNR@SiO ${ }_{2}{ }^{45}$

The ${ }^{1} \mathrm{O}_{2}$ generation ability of AuNRs, AuNR@SiO $\mathrm{S}_{2}$ and TetSiPc@AuNR@SiO ${ }_{2}$ was evaluated by using 9,10-anthracenediylbis(methylene)dimalonic acid (ABDA) as a probe. ${ }^{20}$ The decrease of the ABDA absorption at $378 \mathrm{~nm}$ as a function of irradiation time was observed upon irradiation at $671 \mathrm{~nm}$ (Fig. S10-S12, $\mathrm{ESI} \dagger$ ). The Tet-SiPc@AuNR@SiO ${ }_{2}$ exhibited the highest ability to produce ${ }^{1} \mathrm{O}_{2}$, followed by AuNR@SiO ${ }_{2}$ and AuNRs (Fig. 2i). The best ${ }^{1} \mathrm{O}_{2}$ generation ability of Tet-SiPc@AuNR@SiO ${ }_{2}$ may be related to the synergistic generation of ${ }^{1} \mathrm{O}_{2}$ by both Tet-SiPc and AuNR@SiO ${ }_{2}$ in the nanosystem. ${ }^{46}$

\subsection{Light-controlled Tet-SiPc release from the nano-switch Tet-SiPc@AuNR@SiO}

Most of the theranostic agents were "always-on" models for therapeutic intervention, leading to a low signal-to-noise ratio 
a

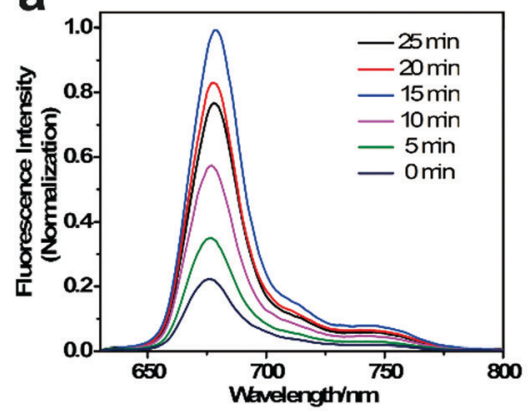

b

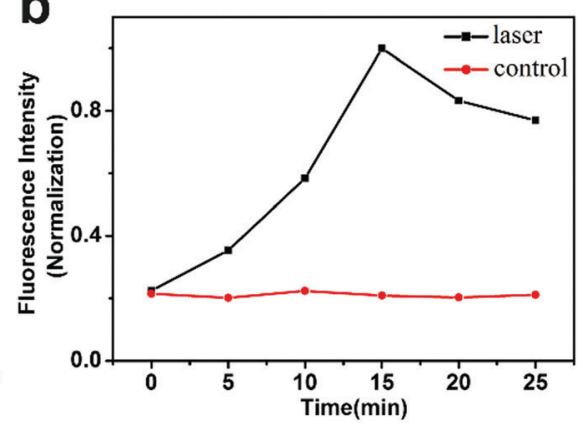

C

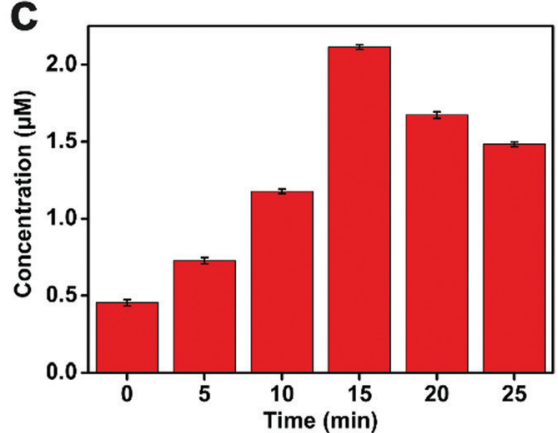

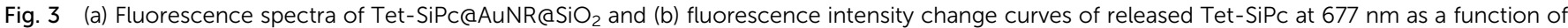

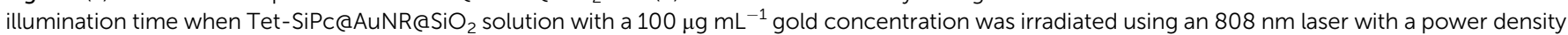

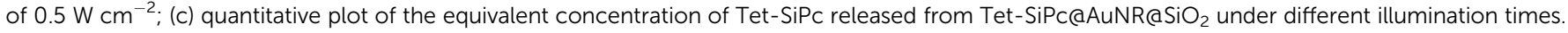
The error bar is shown as the standard deviation from three experiments.

and microbial drug resistance. The nanomaterials for controlled release can effectively overcome these deficiencies.

In order to confirm that Tet-SiPc@AuNR@SiO ${ }_{2}$ is an excellent light-controlled nano-switch, a series of experiments were carried out. The fluorescence of Tet-SiPc in Tet-SiPc@AuNR@SiO ${ }_{2}$ was quenched by AuNR@SiO ${ }_{2}$ without irradiation. Upon irradiation with NIR light, Tet-SiPc was released from Tet-SiPc@AuNR@SiO
(Fig. 3a). The amount of Tet-SiPc released from Tet-SiPc@ AuNR@SiO ${ }_{2}$ was quantified using fluorescence spectra (Fig. 3b and c). The photothermal effect of Tet-SiPc@AuNR@SiO ${ }_{2}$ could change the exothermic adsorption equilibrium and then promoted the release of Tet-SiPc. But the irradiation time was over $15 \mathrm{~min}$, and a decrease in the fluorescence intensity of Tet-SiPc was observed, which may be caused by the photobleaching of

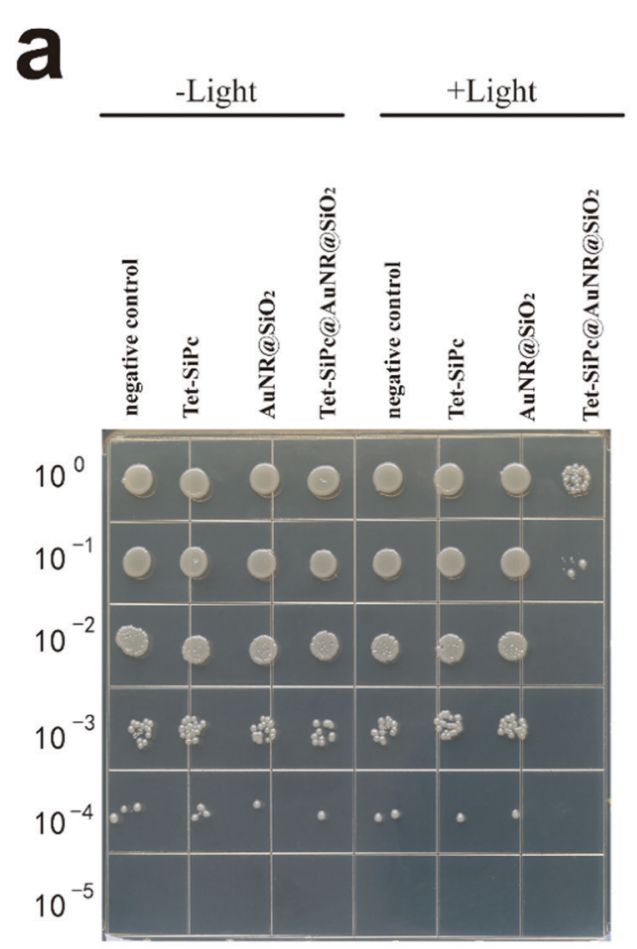

\section{b}

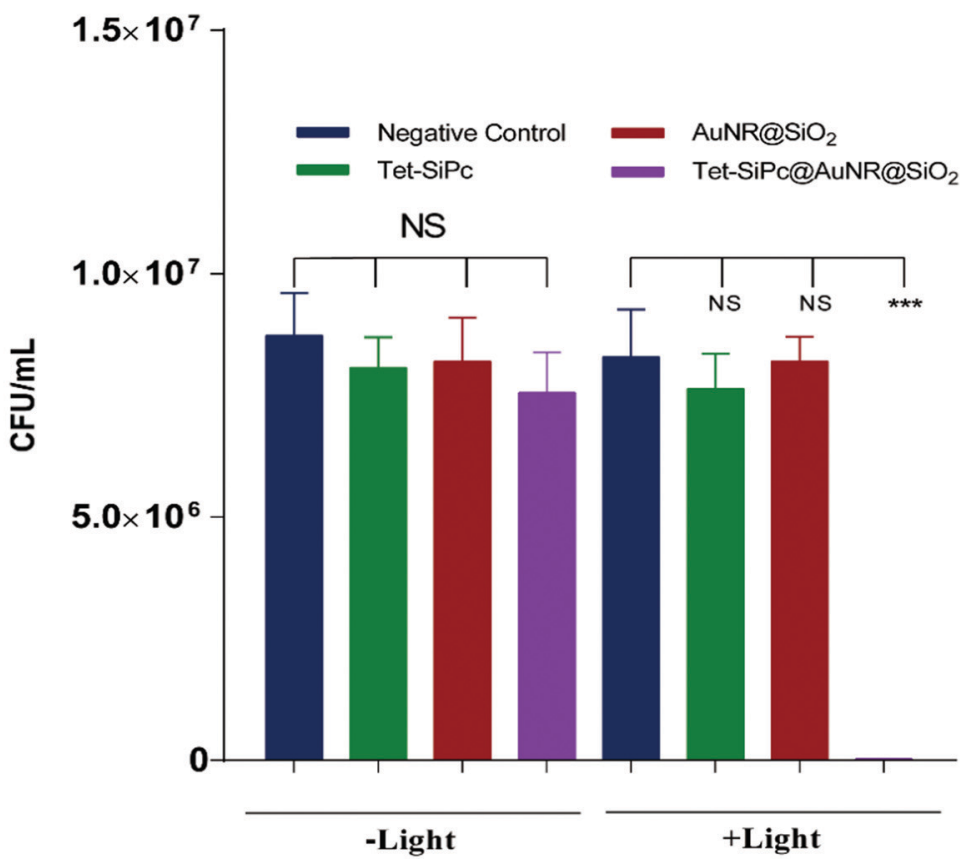

Fig. 4 Antibacterial activity of Tet-SiPc, AuNRs, AuNR@SiO ${ }_{2}$ and Tet-SiPc@AuNR@SiO 2 against $E$. coli DH5 $\alpha$ strain. (a) Colony assay was performed on E. coli DH5 $\alpha$ treated with Tet-SiPc, AuNRs, AuNR@SiO 2 and Tet-SiPc@AuNR@SiO ${ }_{2}$ dissolved in water or $10 \%$ DMSO aqueous solution. The concentration of Tet-SiPc was $50 \mu \mathrm{M}$, the Tet-SiPc concentration in Tet-SiPc@AuNR@SiO 2 was $50 \mu \mathrm{M}$ and the gold concentration in AuNRs, AuNR@SiO ${ }_{2}$ and Tet-SiPc@AuNR@SiO ${ }_{2}$ was $100 \mu \mathrm{g} \mathrm{mL}^{-1}$. After laser irradiation $\left(808 \mathrm{~nm}\right.$ laser light at $0.5 \mathrm{~W} \mathrm{~cm}^{-2}$ for $5 \mathrm{~min}$, followed by $671 \mathrm{~nm}$ laser irradiation for $10 \mathrm{~min}$ with a power density of $100 \mathrm{~mW} \mathrm{~cm}^{-2}$ ), E. coli $\mathrm{DH} 5 \alpha$ solutions were diluted in 10 -fold serial dilutions and $5 \mu \mathrm{L}$ of the diluted solution was dropped on the LB plate; (b) colony forming units (CFU) of E. coli DH5 $\alpha$ treated with Tet-SiPc, AuNRs, AuNR@SiO 2 and Tet-SiPc@AuNR@SiO 2 dissolved in water or $10 \%$ DMSO aqueous solution. The concentration of Tet-SiPc was $50 \mu \mathrm{M}$, the Tet-SiPc concentration in Tet-SiPc@AuNR@SiO ${ }_{2}$ was $50 \mu M$ and the gold concentration in AuNRs, AuNR@SiO ${ }_{2}$ and Tet-SiPc@AuNRaSiO 2 was $100 \mu \mathrm{g} \mathrm{mL}^{-1}$. The data are expressed as means $\pm \mathrm{SD}$ of three experiments. NS means no statistical significance, ${ }^{* \star *} P<0.001$. 
Tet-SiPc by irradiation or the aggregation behaviour of Tet-SiPc released into water. Light can manipulate very precisely to release the Tet-SiPc in the Tet-SiPc@AuNR@SiO ${ }_{2}$, which provides a strategy to prevent the bacteria from developing drug resistance by long exposure to the Tet-SiPc@AuNR@SiO ${ }_{2}$ in antibacterial application.

\subsection{Antibacterial activity of the nano-switch Tet- SiPc@AuNR@SiO 2 against E. coli DH5 $\alpha$}

E. coli $\mathrm{DH} 5 \alpha$ was selected as a model to evaluate the antibacterial activity of Tet-SiPc@AuNR@SiO ${ }_{2}$. Upon irradiation, both TetSiPc and AuNR@SiO ${ }_{2}$ did not show obvious antibacterial efficacies against DH5 $\alpha$, indicating that the photodynamic efficacy of Tet-SiPc or the photothermal efficacy of AuNR@SiO $\mathrm{Al}_{2}$ alone did not present enough antibacterial activity against DH5 $\alpha$.
The Tet-SiPc@AuNR@SiO ${ }_{2}$ exhibited a significant antibacterial efficacy with a killing rate of $99.83 \%$ (Fig. 4), which can be explained by the fact that AuNR@SiO ${ }_{2}$ served as a photothermal agent to absorb the energy of the NIR laser and convert it into heat energy, which triggered the release of Tet-SiPc from Tet-SiPc@AuNR@SiO ${ }_{2}$ and promoted the released Tet-SiPc to produce ${ }^{1} \mathrm{O}_{2}$ to kill the bacteria through the synergistic photodynamic and photothermal effects. ${ }^{47}$

\subsection{Antibacterial activity of the nano-switch Tet-} SiPc@AuNR@SiO ${ }_{2}$ against antibiotic-resistant $E$. coli DH5 $\alpha$ strains

We wondered whether the Tet-SiPc@AuNR@SiO ${ }_{2}$ exhibited the same effect in killing the antibiotic-resistant bacteria as the non-resistant bacteria. Three antibiotic-resistant DH5 $\alpha$ strains,

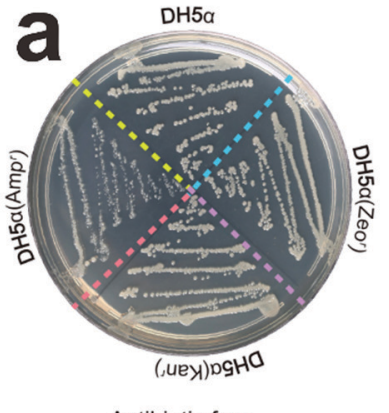

Antibiotic free
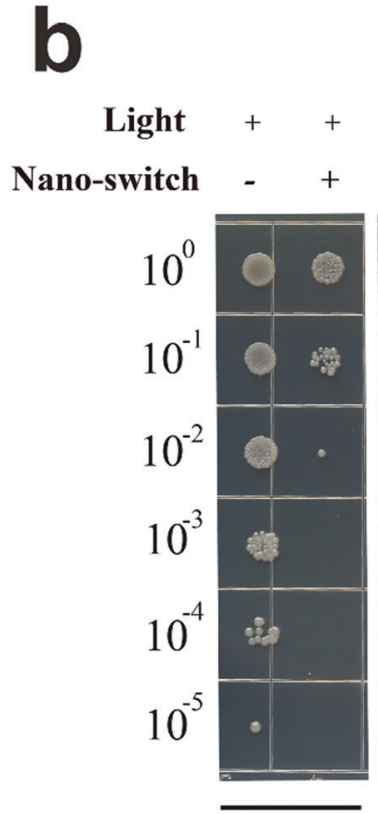

DH5x

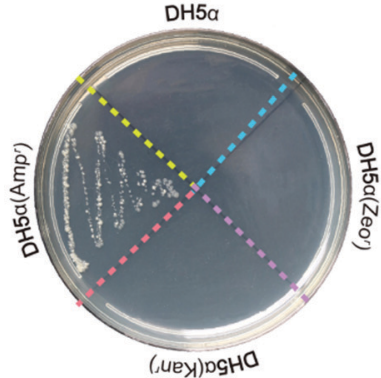

Ampicillin $(100 \mu \mathrm{g} / \mathrm{ml})$

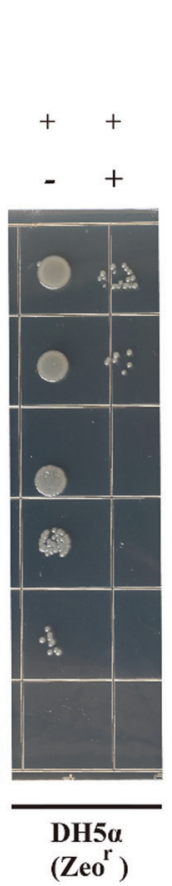

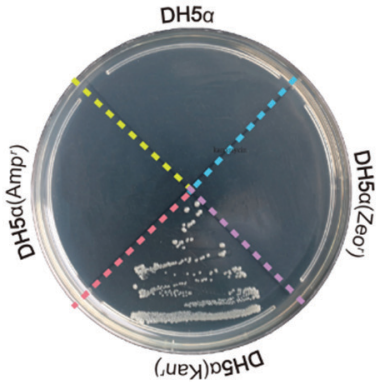

Kanamycin $(50 \mu \mathrm{g} / \mathrm{ml})$

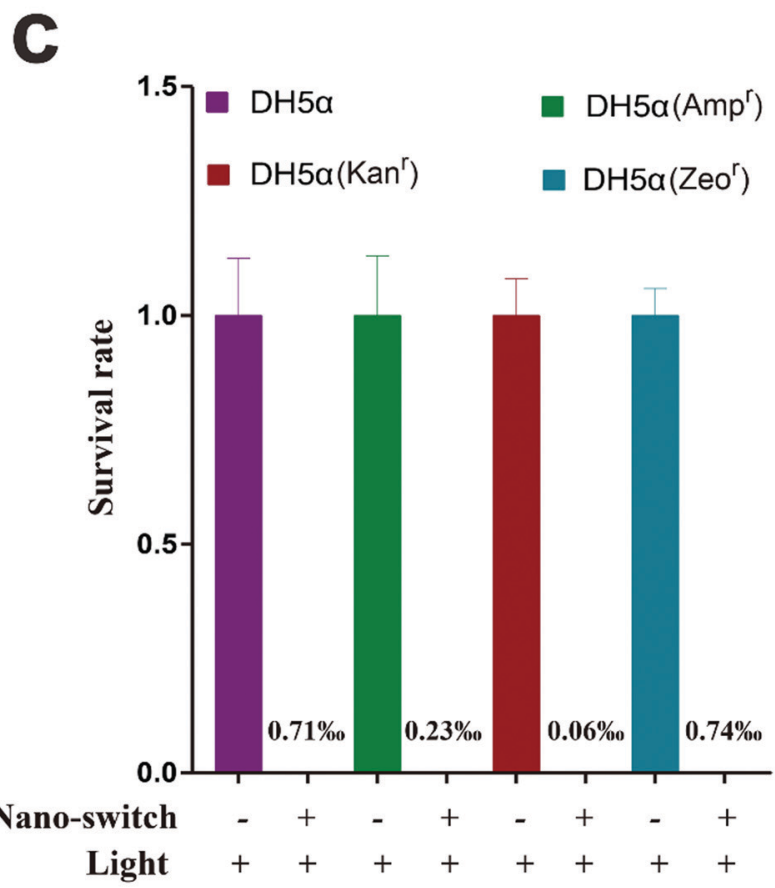

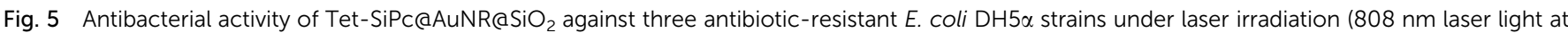

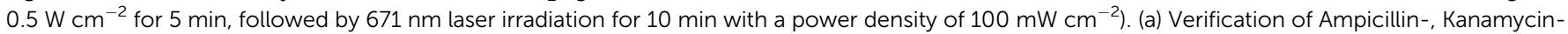

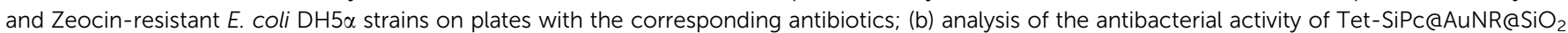

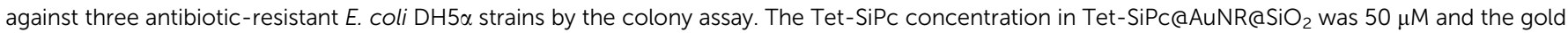

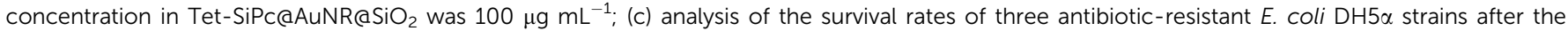

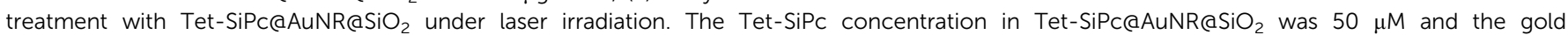
concentration in Tet-SiPc@AuNRaSiO 2 was $100 \mu \mathrm{g} \mathrm{mL}^{-1}$. The data are expressed as means $\pm \mathrm{SD}$ of three experiments. 
a

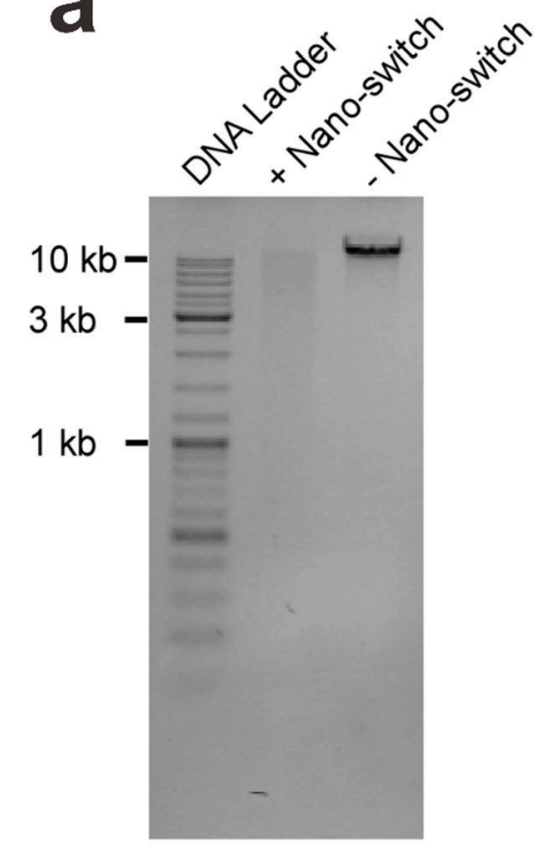

b

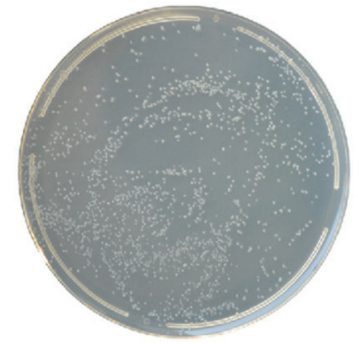

E. coli DH5 a

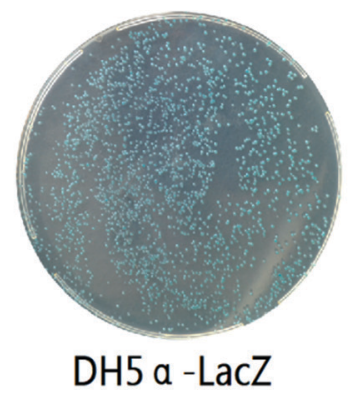

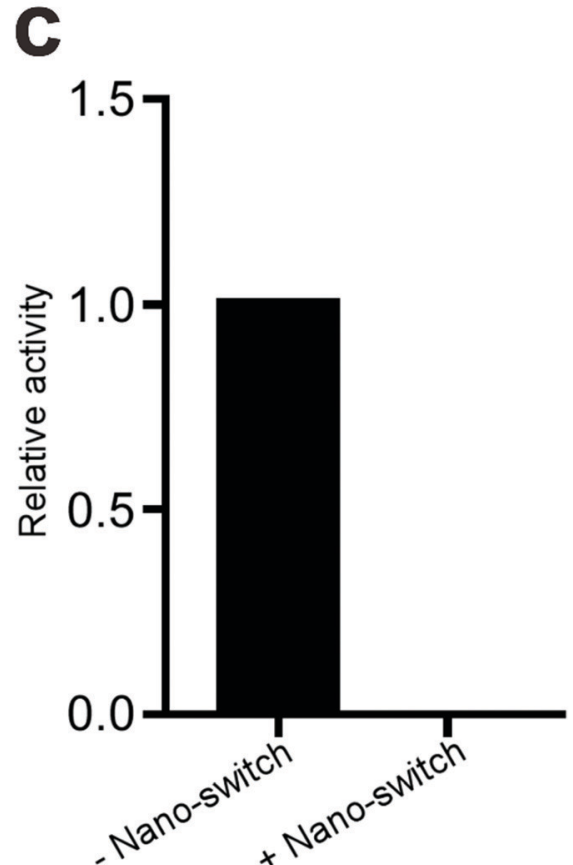

Fig. 6 Tet-SiPc@AuNR@SiO ${ }_{2}$ impaired genomic DNA and enzymes of DH5 $\alpha$ cells. (a) The genomic DNA of DH5 $\alpha$ was degraded after the treatment with Tet$\mathrm{SiPc}\left(\mathrm{AuNR} @ \mathrm{SiO}_{2}\right.$ (the Tet-SiPc concentration in Tet-SiPc(aANR@SiO 2 was $50 \mu \mathrm{M}$ and the gold concentration in Tet-SiPc@AuNR@SiO ${ }_{2}$ was $100 \mu \mathrm{g} \mathrm{mL}^{-1}$ ) under laser irradiation ( $808 \mathrm{~nm}$ laser at $0.5 \mathrm{~W} \mathrm{~cm}^{-2}$ for $5 \mathrm{~min}$, followed by $671 \mathrm{~nm}$ laser irradiation for $10 \mathrm{~min}$ with a power density of $100 \mathrm{~mW} \mathrm{~cm}^{-2}$ ); (b) the $\mathrm{DH} 5 \alpha$-LacZ strain successfully expressed the reporter $\beta$-galactosidase; (c) analysis of $\beta$-galactosidase activity with or without treatment with the Tet$\mathrm{SiPc} @ A u n R @ \mathrm{SiO}_{2}$ (the Tet-SiPc concentration in Tet-SiPc@AuNR@SiO 2 was $50 \mu \mathrm{M}$ and the gold concentration in Tet-SiPc@AuNR@SiO ${ }_{2}$ was $100 \mu \mathrm{g} \mathrm{mL}^{-1}$ ) under laser irradiation ( $808 \mathrm{~nm}$ laser light at $0.5 \mathrm{~W} \mathrm{~cm}^{-2}$ for $5 \mathrm{~min}$, followed by $671 \mathrm{~nm}$ laser irradiation for 10 min with a power density of $100 \mathrm{~mW} \mathrm{~cm}^{-2}$ ).

DH5 $\alpha\left(\mathrm{Amp}^{\mathrm{r}}\right)$, DH5 $\alpha\left(\operatorname{Kan}^{\mathrm{r}}\right)$ and DH5 $\alpha\left(\mathrm{Zeo}^{\mathrm{r}}\right)$, were obtained through the transformation of plasmids pUC18, pET28a and pPICZa into DH5 $\alpha$ cells, respectively. Their ability to resist antibiotics was confirmed on the plates containing the corresponding antibiotics (Fig. 5a). The antibacterial activity of Tet-SiPc@AuNR@SiO ${ }_{2}$ against the antibiotic-resistant DH5 $\alpha$ was evaluated. The results showed that the Tet-SiPc@AuNR@ $\mathrm{SiO}_{2}$ also exhibited strong antibacterial activity against all DH5 $\alpha$ $\left(\mathrm{Amp}^{\mathrm{r}}\right), \mathrm{DH} 5 \alpha\left(\operatorname{Kan}^{\mathrm{r}}\right)$ and DH5 $\alpha\left(\mathrm{Zeo}^{\mathrm{r}}\right)$ strains (Fig. 5b and c).

\subsection{Antibacterial mechanism of the nano-switch Tet- $\mathrm{SiPc@AuNR@SiO} 2$}

DNA and enzymes are the most important biological macromolecules in bacterial cells. DNA stores the genetic information of bacteria and controls the metabolism of bacteria. ${ }^{48}$ Enzymes catalyse nearly all the chemical reactions in cells and are also essential for cell survival. We suspected that Tet-SiPc@ AuNR@SiO ${ }_{2}$ impaired DNA and enzymes in cells under laser light, which caused the death of cells. The genomic DNA of DH5 $\alpha$ treated with or without Tet-SiPc@AuNR@SiO ${ }_{2}$ was isolated and analysed via agarose gel electrophoresis. The result was shown in Fig. 6a. The genomic DNA treated with TetSiPc@AuNR@SiO ${ }_{2}$ upon irradiation showed a smear band in the agarose gel, suggesting that DNA was fragmented.

The $\beta$-galactosidase encoded by the LacZ gene is a favourable reporter for the quantitative analysis of enzymatic activity in microorganisms. In this study, $\beta$-galactosidase was used as a reporter to evaluate the enzymatic damage of $\mathrm{DH} 5 \alpha$ treated with Tet-SiPc@AuNR@SiO ${ }_{2}$ under laser irradiation. $\beta$-galactosidase activity is deficient in $\mathrm{DH} 5 \alpha$ because of the $\triangle \mathrm{M} 15$ mutation of the Lac $\mathrm{Z}$ gene. In order to restore the $\beta$-galactosidase activity, we constructed a plasmid expressing the LacZ gene and transformed it into $\mathrm{DH} 5 \alpha$, named DH5 $\alpha$-LacZ. The DH5 $\alpha$-LacZ strain showed blue colonies in the plate containing $\mathrm{X}$-Gal, indicating that the $\beta$-galactosidase activity was regained in DH5 $\alpha$-LacZ (Fig. 6b). The $\beta$-galactosidase activity of the DH5 $\alpha$-LacZ strain treated with or without Tet-SiPc@AuNR@ $\mathrm{SiO}_{2}$ was analysed. The result showed that the $\beta$-galactosidase activity of DH5 $\alpha$-LacZ was totally undetectable after the treatment of Tet-SiPc@AuNR@SiO ${ }_{2}$ under laser irradiation (Fig. 6c).

The possible antibacterial mechanism is that the Tet-SiPc@ AuNR@SiO $\mathrm{S}_{2}$ more efficiently generated heat and ROS upon irradiation. The enzymes and DNA in cells are denatured at high temperatures, and these denatured macromolecules are more vulnerable to impair by ROS. The synergistic photothermal and photodynamic effect gives the Tet-SiPc@AuNR@ $\mathrm{SiO}_{2}$ a more effective ability to kill $E$. coli cells.

\section{Conclusions}

In this work, we successfully constructed a near-infrared lightcontrolled nano-switch Tet-SiPc@AuNR@SiO ${ }_{2}$. This nanoswitch was assembled through adsorption of Tet-SiPc in the mesoporous silica layer of AuNR@SiO 
realized precisely controlled release of Tet-SiPc from AuNR@ $\mathrm{SiO}_{2}$ and the generation of ROS as well as excellent photothermal conversion efficiency through simple light irradiation and exhibited a synergistic photothermal and photodynamic effects in killing both $E$. coli and antibiotic-resistant E. coli strains. The degradation of genomic DNA and the loss of enzyme activity in $E$. coli cells after the treatment with TetSiPc@AuNR@SiO ${ }_{2}$ under irradiation could be the main causes of bacteria killing.

\section{Author contributions}

Qiuhao Ye: methodology, data curation, formal analysis, writing review \& editing. Shuanghuang Xiao: investigation, writing original draft. Ting Lin: investigation. Yufeng Jiang: investigation, methodology, formal analysis. Yiru Peng: conceptualization, methodology, project administration, supervision, writing review \& editing, funding acquisition. Yide Huang: methodology, supervision, writing - review \& editing.

\section{Conflicts of interest}

There are no conflicts to declare.

\section{Acknowledgements}

This work was supported by the National Key Basic Research Program of China (973 project) (2015CB35200), the National Natural Science Foundation of China (21274021), the Natural Science Foundation of Fujian (2019Y0007), the Joint Funds of Fujian Provincial Health and Education Research (2019-WJ-23), the Scientific Research Innovation Team Construction Programme of Fujian Normal University (IRTL 1702), the scientific research innovation program "Xiyuanjiang River Scholarship" of College of Life Sciences, Fujian Normal University and the Special Funds of the Central Government Guiding Local Science and Technology Development (2020L3008).

\section{Notes and references}

1 M. Bassetti, G. Poulakou, E. Ruppe, E. Bouza, S. J. Van Hal and A. Brink, Intensive Care Med., 2017, 43, 1464-1475.

2 J. M. Stokes, K. Yang, K. Swanson, W. Jin, A. Cubillos-Ruiz, N. M. Donghia, C. R. MacNair, S. French, L. A. Carfrae, Z. Bloom-Ackerman, V. M. Tran, A. Chiappino-Pepe, A. H. Badran, I. W. Andrews, E. J. Chory, G. M. Church, E. D. Brown, T. S. Jaakkola, R. Barzilay and J. J. Collins, Cell, 2020, 180, 688-702.

3 T. Wi, M. M. Lahra, F. Ndowa, M. Bala, J. R. Dillon, P. Ramon-Pardo, S. R. Eremin, G. Bolan and M. Unemo, PLoS Med., 2017, 14, e1002344.

4 M. E. A. D. Kraker, A. J. Stewardson and S. Harbarth, PLoS Med., 2016, 13, e1002184.
5 E. Tacconelli, E. Carrara, A. Savoldi, S. Harbarth, M. Mendelson, D. L. Monnet, C. Pulcini and G. Kahlmeter, Lancet Infect. Dis., 2018, 18, 318-327.

6 T. Guo, Y. Lin, G. Jin, R. Weng, J. Song, X. Liu, G. Huang, L. Hou and H. Yang, Chem. Commun., 2019, 55, 850-853.

7 N. Yang, C. Wang, X. Wang and L. Li, Nanotechnology, 2018, 29, 175601.

8 W.-Y. Chen, H.-Y. Chang, J.-K. Lu, Y.-C. Huang, S. G. Harroun, Y.-T. Tseng, Y.-J. Li, C.-C. Huang and H.-T. Chang, Adv. Funct. Mater., 2015, 25, 7189-7199.

9 M. L. Xu, L. Y. Guan, S. K. Li, L. Chen and Z. Chen, Chem. Commun., 2019, 55, 5359-5362.

10 X. Chen, S. Wu, D. Ma, J. Chen, Q. Guo, X. Han, K. Chen, H. Yang, Y. Huang and Y. Peng, Chem. Commun., 2018, 54, 13279-13282.

11 X. Yang, J. Li, T. Liang, C. Ma, Y. Zhang, H. Chen, N. Hanagata, H. Su and M. Xu, Nanoscale, 2014, 6, 10126-10133.

12 W. Zeng, H. Zhang, Y. Deng, A. Jiang, X. Bao, M. Guo, Z. Li, M. Wu, X. Ji, X. Zeng and L. Mei, Chem. Eng. J., 2020, 389, 124494.

13 Z. H. Yu, X. Li, F. Xu, X. L. Hu, J. Yan, N. Kwon, G. R. Chen, T. Tang, X. Dong, Y. Mai, D. Chen, J. Yoon, X. P. He and H. Tian, Angew. Chem., Int. Ed., 2020, 59, 3658-3664.

14 X. Chen, Q. Zhang, J. Li, M. Yang, N. Zhao and F. J. Xu, ACS Nano, 2018, 12, 5646-5656.

15 Y. Wang, Q. Cui, X. Zhao, T. Qin, W. Wang, H. Sun, H. Zhu, H. Guo and H. Sun, RSC Adv., 2018, 8, 41454-41463.

16 C. Li, Y. Zhang, Z. Li, E. Mei, J. Lin, F. Li, C. Chen, X. Qing, L. Hou, L. Xiong, H. Hao, Y. Yang and P. Huang, Adv. Mater., 2018, 30, 1706150.

17 Y. Liu, P. Bhattarai, Z. Dai and X. Chen, Chem. Soc. Rev., 2019, 48, 2053-2108.

18 J. Liu, C. Detrembleur, M. C. De Pauw-Gillet, S. Mornet, C. Jerome and E. Duguet, Small, 2015, 11, 2323-2332.

19 X. Cui, W. Cheng and X. Han, J. Mater. Chem. B, 2018, 6, 8078-8084.

20 K. Turcheniuk, V. Turcheniuk, C. H. Hage, T. Dumych, R. Bilyy, J. Bouckaert, L. Heliot, V. Zaitsev, R. Boukherroub and S. Szunerits, Chem. Commun., 2015, 51, 16365-16368.

21 J. Sun, Y. Zhang, J. Su, T. Dai, J. Chen, L. Zhang, H. Wang, W. Liu, M. Huang and Z. Chen, Dyes Pigm., 2020, 179, 108392.

22 W. Liu, Y. Zhang, W. You, J. Su, S. Yu, T. Dai, Y. Huang, X. Chen, X. Song and Z. Chen, Nanoscale, 2020, 12, 13948-13957.

23 E. Dube, D. O. Oluwole, N. Nwaji and T. Nyokong, Spectrochim. Acta, Part A, 2018, 203, 85-95.

24 P. Garcia Calavia, I. Chambrier, M. J. Cook, A. H. Haines, R. A. Field and D. A. Russell, J. Colloid Interface Sci., 2018, 512, 249-259.

25 L. Lamch, J. Kulbacka, M. Dubinska-Magiera, J. Saczko and K. A. Wilk, Photodiagn. Photodyn. Ther., 2019, 25, 480-491.

26 Z. Wang, T. Jia, Q. Sun, Y. Kuang, B. Liu, M. Xu, H. Zhu, F. He, S. Gai and P. Yang, Biomaterials, 2020, 228, 119569.

27 X. Li, D. Lee, J. D. Huang and J. Yoon, Angew. Chem., Int. Ed., 2018, 57, 9885-9890. 
28 E. Lee, X. Li, J. Oh, N. Kwon, G. Kim, D. Kim and J. Yoon, Chem. Sci., 2020, 11, 5735-5739.

29 H. H. Mohamed, I. Hammami, S. Akhtar and T. E. Youssef, Composites, Part B, 2019, 176, 107314.

30 A. Galstyan, A. Ricker, H. Nüsse, J. Klingauf and U. Dobrindt, ACS Appl. Bio Mater., 2019, 3, 400-411.

31 Y. Jia, J. Li, J. Chen, P. Hu, L. Jiang, X. Chen, M. Huang, Z. Chen and P. Xu, ACS Appl. Mater. Interfaces, 2018, 10, 15369-15380.

32 K. Kuninobu, A. Tadaaki, M. Noriyuki, H. Makoto and S. Tamotsu, Chem. Lett., 2002, 966-967.

33 N. Nishiyama, Y. Nakagishi, Y. Morimoto, P. S. Lai, K. Miyazaki, K. Urano, S. Horie, M. Kumagai, S. Fukushima, Y. Cheng, W. D. Jang, M. Kikuchi and K. Kataoka, J. Controlled Release, 2009, 133, 245-251.

34 S. Bhana, R. O'Connor, J. Johnson, J. D. Ziebarth, L. Henderson and X. Huang, J. Colloid Interface Sci., 2016, 469, 8-16.

35 S. J. Wittenberger, Org. Prep. Proc. Int., 1994, 26, 499-531.

36 S. Ganapaty, P. Ramalingam and C. B. Rao, Indian J. Heterocycl. Chem., 2007, 16, 283-286.

37 T. I. Bruce, N. Diel, K. F. Schoch, T. J. Marks, J. W. Lyding and C. R. Kannewurf, J. Am. Chem. Soc., 1983, 105, 1551-1567.

38 N. Babak and A. E. Mostafa, Chem. Mater., 2003, 15, 1957-1962.
39 I. Gorelikov and N. Matsuura, Nano Lett., 2008, 8, 369-373. 40 X. H. Peng, S. F. Chen, B. Y. Zheng, B. D. Zheng, Q. F. Zheng, X. S. Li, M. R. Ke and J. D. Huang, Tetrahedron, 2017, 73, 378-384.

41 X.-F. Zhang and H.-J. Xu, J. Chem. Soc., Faraday Trans., 1993, 89, 3347-3351.

42 N. Nwahara, J. Britton and T. Nyokong, J. Coord. Chem., 2017, 70, 1601-1616.

43 N. A. Kuznetsova, N. S. Gretsova and E. A. Kalmykova, Russ. J. Gen. Chem., 2000, 70, 133-140.

44 J. Geng, Z. Zhu, W. Qin, L. Ma, Y. Hu, G. G. Gurzadyan, B. Z. Tang and B. Liu, Nanoscale, 2014, 6, 939-945.

45 J. Peng, L. Zhao, X. Zhu, Y. Sun, W. Feng, Y. Gao, L. Wang and F. Li, Biomaterials, 2013, 34, 7905-7912.

46 N. T. Chen, K. C. Tang, M. F. Chung, S. H. Cheng, C. M. Huang, C. H. Chu, P. T. Chou, J. S. Souris, C. T. Chen, C. Y. Mou and L. W. Lo, Theranostics, 2014, 4, 798-807.

47 J. Wang, Y. Liu, Y. Ma, C. Sun, W. Tao, Y. Wang, X. Yang and J. Wang, Adv. Funct. Mater., 2016, 26, 7516-7525.

48 N. Jimenez-Garrido, L. Perello, R. Ortiz, G. Alzuet, M. GonzalezAlvarez, E. Canton, M. Liu-Gonzalez, S. Garcia-Granda and M. Perez-Priede, J. Inorg. Biochem., 2005, 99, 677-689. 